\title{
Cuestión social y constitución del sujeto receptor en la Asignación Universal por Hijo para Protección Social
}

\author{
Mariana Servio \\ Universidad Nacional de Rosario (UNR)
}

Cuestión social y constitución del sujeto receptor en la Asignación Universal por Hijo para Protección Social

Resumen: El artículo analiza algunos aspectos de la Asignación Universal por Hijo para Protección Social, medida que desde su implementación en el año 2009 la colocan en el centro de las reflexiones actuales en lo que respecta al rol del Estado en materia protección social en Argentina. Partiendo de identificar líneas de continuidad y puntos de ruptura que la Asignación Universal introduce respecto de la lógica de intervención social característica de la racionalidad política neoliberal, se avanza en detectar qué supone de nuevo como así también qué de permanente, en términos de cómo es entendida, pensada y abordada la cuestión social y sus implicancias en términos de la constitución del sujeto receptor de la política social.

Palabras clave: Asignación Universal. Cuestión social. Sujeto receptor.

A questão social e a constituição do sujeito receptor no Subsídio Universal por Filho para a Proteção Social

Resumo: O artigo analisa alguns aspectos do Subsídio Universal por Filho para a Proteção Social. Essa medida, que foi estabelecida em 2009, a coloca no centro das atuais reflexões sobre a função do Estado em relação à proteção social em Argentina. A partir da identificação das líneas de continuidade e pontos de ruptura que o Subsídio Universal introduz sobre a lógica da intervenção social, que é uma característica da racionalidade política neoliberal, é possível avançar para detectar o que supõe de novo e também de permanente, em termos de como é entendida, pensada e abordada a questão social e suas implicações sobre a constituição do sujeito receptor da política social.

Palavras-chave: Subsídio Universal. Questões sociais. Sujeito receptor.

The "Social Question" and the Constitution of the Recipient in the Universal Child Allowance for Social Protection

Abstract: This article analyzes some aspects of the Universal Child Allowance for social protection, a measure that since its implementation in 2009 has been at the center of the current reflection on the role of the state in social protection in Argentina. The paper identifies lines of continuity and points of rupture that the Universal Allowance has introduced in relation to the logic of social intervention characteristic of the neoliberal political rationality. It detects what is new and what has remained in terms of how "the social question" is thought of and addressed and its implications in terms of the constitution of the individual recipient of the social policy.

Keywords: Universal Allowance. Social Question. Recipient. 


\section{Introducción}

El presente trabajo se propone analizar algunos aspectos de la Asignación Universal por Hijo para Proteccón Social (en adelante: AUH), a partir de la siguiente hipótesis: la AUH pone en tensión diferentes lógicas de intervención social que responden a maneras divergentes de interrogar la cuestión social. Intentaremos mostrar esa tensión, al mismo tiempo que poner de manifiesto los efectos, también contradictorios, en la constitución de los sujetos receptores de dicha política social, programa que ha marcado un punto de inflexión en los exámenes que se venían realizando en el ámbito académico acerca de la política social en general, y de la política asistencial en particular, en que las discusiones giraban en torno a las críticas al modelo signado por los organismos de crédito internacionales, pos Consenso de Washington. Esta inflexión, sin embargo, obliga a mirar la AUH en relación a la programática neoliberal, no superada.

Es decir, intentaremos mostrar que la AUH plantea tanto líneas de continuidad como también puntos de ruptura con la lógica de intervención social que caracteriza la racionalidad política neoliberal.

\section{Claves conceptuales}

Por racionalidad política entendemos, siguiendo a Giavedoni (2012a), formas de pensar un problema, de constituirlo, de hacerlo inteligible a través de determinadas características y, al hacerlo pensable, gobernarlo. Gobernar una esfera, en el planteo del autor, supone hacer pensable una realidad, y una manera de formular implícitamente modos de actuar sobre ella. Igualmente, las racionalidades políticas evidencian cierta naturalización sobre la manera en que se ejerce el poder, quién lo ejerce y sobre qué esferas debe ser ejercido. Es materializado, asimismo, en los discursos políticos que formulan y justifican ciertos esquemas de la realidad, en los análisis, informes y documentos de expertos, en informes de organismos internacionales etc.

... la AUH pone en tensión
diferentes lógicas de
intervención social que
responden a maneras
divergentes de interrogar la
cuestión social. Intentaremos
mostrar esa tensión, al mismo
tiempo que poner de manifiesto
los efectos, también
contradictorios, en la
constitución de los sujetos
receptores de dicha política
social,...

Este planteo tiene puntos de contacto con el de Sonia Álvarez Leguizamón (2006), quien nos muestra cómo las políticas sociales - como una forma particular de vínculos sociales recíprocos entre el Estado, el mercado, la familia y las comunidades, que adquirió la intervención social moderna sobre las poblaciones sobrantes percibidas como amenaza o a ciertos trabajadores y/o ciudadanos que era preferible integrar - van constituyendo sujetos, ya sea reforzando derechos como reproduciendo o creando nuevas desigualdades y configuraciones tutelares. En este sentido "las políticas sociales modernas expresan estilos o artes de gobernar particulares sobre ciertas poblaciones las que se materializan en complejas tecnologías, dispositivos y sistemas de enunciados que permiten el gobierno de los hombres sobre otros hombres, tanto bajo relaciones tutelares como contractuales (a veces asociadas con derechos), tanto integrando a algunas poblaciones como expulsando otras a los márgenes" (ÁLVAREZ LEGUIZAMÓN, 2006, p.88).

Por su parte, Estela Grassi (2006) conceptualiza la política social como la manera en que la cuestión social es constituida en cuestión de Estado. En primer lugar, por cuestión social concibe la puesta en escena de la falla estructural del capitalismo, entendido éste como modo de producción, es decir, de la tensión y contradicción entre la igualdad formal-cívico-jurídico-política y la desigualdad estructural socio económica. La política social como orientación normativa en lo que se refiere a la reproducción de la vida social y de sus membros, lo que incluye la reproducción de la fuerza de trabajo, se constituye en un proceso de hegemonización. Esto significa, por medio de una disputa por el sentido general de unidad de la sociedad, que obstruya la fractura original y que solucione el problema de la legitimidad. Asimismo, Grassi plantea que la cuestión social se particulariza en problemas sociales, que expresan el modo en que aquella tensión fundante o constitutiva de la sociedad capitalista es interpretada, interrogada, ordenada y canalizada en cada momento histórico. De este modo, la definición del problema social es objeto de una disputa simbólica y 
teórica, que enmascara los diferentes intereses para orientar la acción en lo que respecta a la solución del mismo, y supone distintas concepciones de la tensión subyacente desposesión/ igualdad- libertad.

Por otro lado, desde una perspectiva inspirada en los planteos de Robert Castel, Soldano y Andrenacci (2006) conceptualizan la política social como un conjunto de intervenciones de la sociedad sobre sí misma, que pautan los modos de funcionamiento de los vectores a través de los cuales individuos y grupos se integran a la sociedad. Los autores sugieren que la clave de esta mirada está en entender cómo la política pública opera sobre los lazos de integración social. La integración de los individuos en la sociedad es una preocupación que Castel coloca en términos de protecciones, andamiaje socio institucional necesario para conjurar los riesgos de desafiliación, y mantener la cohesión social. En este sentido, este planteo toma distancia de las perspectivas que abordan la política social como sector dentro de las políticas públicas, o la sumatoria de instituciones, para comenzar a mirarla como un enfoque, una función o una lógica de intervención, inherente a los modos en que se define y metamorfosea la cuestión social. Siguiendo a Castel (2004a, p. 20), "la 'cuestión social' es una aporía fundamental en la cual la sociedad experimenta el enigma de su cohesión y trata de conjurar el riesgo de su fractura. Es un desafío que interroga, pone de nuevo en cuestión la capacidad de una sociedad (lo que en términos políticos se denomina una nación) para existir como un conjunto vinculado por las relaciones de interdependencia".

Por su parte, Susana Murillo (2006, p. 11) expresa que la cuestión social se refiere al síntoma de la desigualdad intrínseca a las relaciones sociales capitalistas: "La cuestión social alude al vacío, a la fractura entre el modelo contractualista del Derecho tal como fue establecido a fines del siglo XVIII y la situación de desigualdad histórico-concreta [...] 'Igualdad' y 'propiedad' son conceptos que en la historia efectiva entran en contradicción constante y generan ese vacío entre ideales y realidad efectiva que se denomina 'cuestión social"". Castel (2004b) va a decir que "lo social" proporciona una propiedad social como analogía a la propiedad privada, otorgando un tejido contenedor y reparador en respuesta a la cuestión social.

Desde la mirada teórica de la función propuesta por Soldano y Andrenacci, aquí sostendremos, en sintonía con el posicionamiento de Melisa Campana (2012, p. 28) que la política social es un enfoque desde el cual es posible detectar un conjunto de funciones de las intervenciones sociales del Estado. Tal como argumenta la autora, apelar a la idea de función sirve para mirar los objetivos estratégicos de las prácticas de gobierno del Estado, función estratégica que denota una finalidad productiva de tales prácticas. Por tanto, "(se trata de) evitar la explicación de los problemas sociales en términos de ausencia, debilidad, incapacidad o disfuncionalidad estatal [...] lo que implica reconocer una función productiva, positiva, estratégica en las prácticas de gobierno". Asimismo, esta perspectiva nos obliga a pensar en los distintos aspectos de las políticas sociales que de un modo u otro reenvían al proceso de integración social.

Por su parte, el argumento que intentamos seguir tiene puntos de contacto con la posición planteada por Grassi (2006) acerca de que el Estado es un actor activo en la producción de los problemas sociales, y que, en la disputa por su definición están también contenidas las maneras de abordarlos.

Por último, la perspectiva introducida por Álvarez Leguizamón (2006; 2011), nos da claves para enfatizar la concepción de políticas sociales como productoras de subjetividades, que expresan estilos distintos de gobernar lo social, dentro de un complejo entramado de relaciones de fuerza.

\section{Cuestión social y política social en la racionalidad política neoliberal}

A partir de las claves conceptuales propuestas, intentaremos mostrar cómo es interrogada la cuestión social en la racionalidad política neoliberal, a qué tipo de intervenciones estatales da lugar, y qué sujeto receptor constituyen tales intervenciones. De este modo, en el siguiente apartado, podremos observar la AUH en relación a este modo de gobernar lo social.

En la lógica de intervención social de la racionalidad política neoliberal, el eje explicativo de la cuestión social está dado por la cuestión pobreza. Giavedoni (2012b) plantea que lo novedoso de las políticas sociales del neoliberalismo es la magnitud que la pobreza comienza a adquirir en los organismos públicos y privados y la reconfiguración que esto supone en términos de cómo es pensada e intervenida la cuestión social, escindiendo las causas constitutivas de la misma. Lo anterior tiene puntos de contacto con el planteo de Fernández Soto, para quien no puede hablarse de pobreza sin referirse a la conformación de la riqueza en la sociedad moderna y los consecuentes niveles de desigualdad social (FERNÁNDEZ SOTO, 2009).

Enfocar la política social desde la óptica de la exclusión social y no como otrora, en que la potencia del vector salarización tendía hacia políticas vinculadas a proteger al trabajador y achicar desigualdades, trae consecuencias en términos del modelo de integración social que se cobija. Éste mudó de aquel en que había una idea de un sujeto colectivo hacia otro en el que la cuestión social se problematiza de manera fragmentaria, dando lugar a intervenciones asistenciales focalizadas en la población que quedó por fuera del nuevo régimen 
de acumulación, pero atribuyendo a debilidades personales el motivo de ese desenganche. Se puede hablar de un proceso de asistencialización de la política social (SOLDANO Y ANDRENACCI, 2006; GRASSI, 2006) el cual imprimió a las intervenciones sociales del Estado un rol residual en el tratamiento de los problemas sociales. Según Grassi, el peso que comenzó a tener la asistencia fue tal porque los nexos entre pobreza y condiciones de trabajo fueron muy endebles: "la mayor liberalización de la fuerza de trabajo y la desestructuración de las instituciones de regulación de su uso y de protección de los trabajadores, fue determinante del mayor peso de la asistencia en la política social, cuyo sujeto no es otro que el trabajador desprotegido, efectiva o potencialmente pobre" (GRASSI, 2006, p. 227).

En este sentido, y tal como lo analiza Denis Merklen (2005, p. 102), este cambio de óptica en la intervención social del Estado permite observar, en términos históricos, cómo lo social pasa de ser monitoreado a través del concepto de trabajador, a ser enfocado en términos de pobreza. Así, el autor demarca dos períodos, analizando dos documentos representativos de sendos procesos:

\begin{abstract}
El primero se abre en 1904 cuando el gobierno encarga al ingeniero Juan Bialet Massé la elaboración de un 'Informe sobre el estado de la clase obrera' como paso previo a la preparación de la primera Ley Nacional del Trabajo. En 1980, la publicación por el Instituto Nacional de Estadísticas y Censos (INDEC) del 'Mapa de la pobreza' clausura este período (y abre el segundo) con una descripción precisa de la distribución territorial de la pobreza, así como de los componentes que definirían este mal. Este informe inauguró las nuevas formas de monitoreo de lo social a través del concepto 'pobreza'.
\end{abstract}

La conversión del trabajador en pobre es un corrimiento semántico que expresa las distintas lógicas en que es pensada la cuestión social y su consecuente tratamiento, marcado ahora por programas de lucha contra la pobreza. Esta estrategia discursiva, plantea Murillo (2007, p. 5), le sirvió a los organismos internacionales de crédito, en tanto la pobreza se tornó un significante para "recomendar un cambio de políticas a los países 'en desarrollo' que culminó con la aplicación de las recomendaciones del 'Consenso de Washington' y la teoría del 'derrame"'. Y, ante el crecimiento de la pobreza y la desigualdad en América Latina, agudizado en la segunda mitad de la década de 1990, una segunda ola de reformas utilizó el significante pobreza, ante el riesgo que conlleva altos índices de pobreza y desigualdad. "De modo que el discurso de los organismos internacionales se pobló de términos que apuntan a luchar o hacer la guerra a la pobreza, al tiempo que de significantes ligados a la idea de empoderamiento y capital social" (MURILLO, 2007, p. 6). Asimismo, poner el eje explicativo de la cuestión social en la pobreza, cercena la discusión en torno a la generación de riqueza y su distribución. "Pensar la agenda social en términos de lucha contra la pobreza tiene consecuencias directas: cuanto más se hace la guerra a la pobreza, más se fija nuestra mirada sobre los pobres, y menos se trabaja sobre los dinamismos sociales que configuran la causa del empobrecimiento" (MERKLEN, 2005, p. 113).

Gobernar la pobreza, en el planteo foucaultiano de Giavedoni (2012a, p. 63), supone al Estado administrando la pobreza, diagnosticándola, controlándola, organizando su gestión:

La noción de 'gobierno' nos indica también que, lejos de intervenciones tímidas, ligeras, improvisadas, carentes de racionalidad alguna sobre un sector de la población en términos de asistencia, como medidas transitorias en su posterior reincorporación al mercado laboral, hay una gestión sobre los mismos, tecnologías específicas, formas de pensar y abordar el problema.

Como sintetiza Campana (2012, p. 148), para el neoliberalismmo la pobreza es un problema de capacidades y disposiciones de los sujetos, es decir, un problema subjetivo, de falta de equipamientos mentales y sociales para afrontar los propios riesgos. En sintonía con el planteo, Sonia Álvarez Leguizamón (2011) entiende que la concepción de pobreza que subyace a esta lógica presume pensarla como producto de la transmisión intergeneracional de ciertos valores y como resultado del déficit de capital humano y/o social. Esta premisa, impulsada por los organismos supranacionales de desarrollo en nuestra región dio lugar a políticas asistenciales focalizadas - focopolíticas en el lenguaje de la autora - para la población definida como objeto de intervención, atribuyendo a debilidades individuales el motivo de las situaciones de pobreza y apuntando a su empoderamiento, capacitación, estímulo, para cortar con tal círculo vicioso y lograr que individuos, grupos y comunidades auto gestionen su propia pobreza. Para lograr el fortalecimiento de la comunidad y potenciar la autoestima individual, las organizaciones de la sociedad civil tienen adjudicado un rol primordial, administrando recursos financieros que se ponen a su disposición. Esta lógica, junto con la de la contraprestación, presente en la mayoría de los programas asistenciales focalizados, tiende a responsabilizar a los sujetos de su situación, y, bajo la excusa de impulsar la participación, se les exige que sean parte de su rehabilitación. La reconfiguración de las protecciones al nivel de su individualización, de acuerdo nos muestra Castel (2010), coloca al individuo dependiendo cada vez 
más de situaciones particulares para ser seleccionado como beneficiario de una protección estatal. Asimismo, debe colaborar activamente con los dispositivos que le son propuestos.

Concluimos planteando que la lógica de intervención en lo social, propia de la racionalidad política neoliberal, tiende a consolidar un esquema fragmentado y desarticulado, donde la cuestión social es problematizada en términos de pobreza, desvinculando las causas constitutivas de la misma y adjudicando a atributos negativos de los sujetos, el motivo de su situación, colocada como déficit o carencia.

\section{Asignación universal por hijo. Inflexión en las protecciones sociales}

Dijimos al comienzo del trabajo, que la Asignación Universal por Hijo presenta rasgos contradictorios, ya que conviven en su interior, aspectos pertenecientes a la lógica de intervención que permea la racionalidad política neoliberal, y aspectos que rompen, o intentan romper, con ese modo de gobernar lo social. Es importante señalar que estas lógicas en tensión, se expresan en un momento de impugnación generalizada a las políticas de corte neoliberal en toda la región ${ }^{2}$. En el caso puntual argentino, luego del período de mayor crisis socioeconómica y convulsión social que culmina con la salida del gobierno de la Alianza ${ }^{3}$, presidido por Fernando De la Rúa, hay una puesta en cuestión, a partir de la presidencia de Néstor Kirchner en el año 2003, de la hegemonía neoliberal y un agudo debate público en torno al conjunto de políticas de estado ${ }^{4}$. Sin dudas, la creación del decreto que instaura la AUH en el año 2009 marcó un punto de inflexión en los exámenes que venían realizándose en el ámbito académico acerca de la política social en general, y de la política asistencial en particular. A partir de entonces, las discusiones remiten necesariamente al análisis de la AUH, como una de las medidas de política social más importantes de los últimos tiempos. Sin embargo, la AUH debe irremediablemente ser mirada en relación a la racionalidad política neoliberal.

Un repaso por las principales características de la medida en cuestión: el decreto de creación de la AUH establece la ampliación del Régimen de Asignaciones Familiares incorporando, en la Ley $\mathrm{N}^{\circ} 24.714$, a los trabajadores desocupados o que se desempeñen en la economía informal. De este modo, el sistema pasó a contemplar un subsistema de base no contributiva, sumándose al ya existente, de base contributiva. El nuevo subsistema está destinado a aquellas niñas, niños y adolescentes menores de dieciocho años, y sin límite de edad para hijos discapacitados, que no tengan otra asignación familiar prevista por la citada ley y que pertenezcan a grupos familiares que se encuentran desocupados o que se desempeñan en la economía informal, además de los monotributistas sociales. Quedan excluidos del beneficio aquellos trabajadores informales que cobren una remuneración superior al salario mínimo, vital y móvil y los monotributistas. Por otra parte, es acumulable hasta un máximo de cinco hijos menores de dieciocho años.

Posteriormente a la creación de la AUH, los trabajadores que forman parte del Régimen Especial de Seguridad Social para Empleados del Servicio Doméstico fueron incorporados por resolución de ANSES 393/ 2009. Igualmente, hacia finales del año 2010, también fueron incluidos al decreto aquellos trabajadores temporarios registrados, durante los meses que no desempeñen su actividad. Asimismo, en el año 2011 fue sumada la Asignación por Embarazo para Protección Social, que incluye a las mujeres embarazadas, a partir de la décimo segunda semana de gestación, incorporando la asignación por embarazo en el decreto modificatorio de la Ley $\mathrm{N}^{\circ} 24714$, dentro del subsistema no contributivo.

Por otra parte, la AUH establece condicionalidades: la acreditación al plan de vacunación obligatorio y controles sanitarios para los niños/as menores de cinco años, y, para los mayores de esa edad, se suma el requisito de asistencia educativa. La manera de gestionar este aspecto consiste en retener el $20 \%$ del monto asignado, por parte de la Administración Nacional de la Seguridad Social (ANSES), liquidado a final de año, ante la comprobación de las condicionalidades.

En primer lugar, señalaremos que hay un punto de inflexión, respecto del lugar que comienza a ocupar la intervención estatal para influir sobre el proceso de integración social. El hecho de que la AUH no esté explícitamente dirigida a las familias pobres, marca un punto de diferenciación con la mayoría de los esquemas de transferencia condicionadas de ingreso, pre existentes en el país, y contemporáneos de la región.

En ese sentido, Hintze y Costa (2010) plantean que, a diferencia del ciclo de hegemonía neoliberal, la década de 1990, en el que la inclusión fue depositada en la asistencia en general y los planes de asistencia al desempleo en particular, la AUH contrapuso la idea de que el Estado debe asumir la obligación de otorgar beneficios de la seguridad social entendidos como derechos, comprometiéndose así activamente con el objetivo de la inclusión, y no de manera residual. Destacan el hecho de que la AUH se haya incorporado al régimen de asignaciones familiares pre existente, lo cual iría en detrimento de provocar estigmatización. Vincular el aporte con la seguridad social implica, para las autoras, igualdad y solidaridad, y reconocimiento de derechos (particularmente del trabajo) y de garantías para la reproducción de la vida. 
En esa línea encontramos los argumentos de Emilia Roca (2010, p. 18), funcionaria del Ministerio de Trabajo, Empleo y Seguridad Social:

La idea es que la extensión de las asignaciones familiares se oriente en el mismo sentido que la decisión, también tomada por el Gobierno Nacional, de aumentar la cobertura de las jubilaciones. Atrás de esto hay una idea que es la de fortalecer a la Seguridad Social como eje de la inclusión social. Es decir, establecer un nuevo estándar de protección social de aquí a futuro con un enfoque de derechos basado en los derechos sociales, en los derechos de la de Seguridad Social, tales como el de las jubilaciones.

En este sentido, Mrejen (2013, p. 332), nos muestra que la AUH posee características propias de la técnica aseguradora, es decir, aparecen en su diseño elementos que habían sido centrales para las racionalidades políticas que configuraron las modalidades de gobierno de lo social durante gran parte del siglo 20 en nuestro país. Pauta de este aspecto es el hecho de que la AUH se erija como una protección asociada al mundo del trabajo y la seguridad social, y el dato no menor de la relación directa del ciudadano con la agencia administradora de la seguridad social a nivel nacional, la Administración Nacional de la Seguridad Social (ANSES).

Sin embargo, como también nos muestra el politólogo rosarino, al mismo tiempo, la AUH presenta características propias de las tecnologías asistenciales focalizadas del gobierno de lo social, fundamentalmente la imposición de las condicionalidades, ciertas exclusiones arbitrarias como el caso del sexto hijo, y el hecho de que la definición de la población objetivo, a menos que se consideren las estadísticas oficiales, termina acotando la posibilidad de inscripción casi exclusivamente a los pobres. En este sentido colocamos que no contemplar a las/ os trabajadores informales con remuneraciones superiores al salario mínimo, vital y móvil, y a los monotributistas, dejando sin cobertura alguna a esa población, atenta, además, con las pretensiones universalistas de la AUH. Y con respecto a las condicionalidades, enfatizamos el hecho de que reproduce la lógica de merecedores/no merecedores, y refuerza la idea que para que una medida sea socialmente aceptada, debe exigirse algo a cambio. De esta manera, se continúa sancionando, se sobrecarga y responsabiliza a sus beneficiários:

Al ser sólo una exigencia de la AUH y no del resto de las asignaciones familiares, parecen suponer que son los sectores más vulnerables quienes necesitan la tutela y la sanción del Estado para cumplir con esas obligaciones, lejos de centrarse en los problemas relacionados con la oferta existente de salud y educación que, como no se puede desconocer, presenta serios déficit de cobertura (ARCIDIÁCONO, CARMONA Y STRASCHNOY,2011, p.11).

En el mismo sentido, esta característica deja entrever una representación moralizante y punitiva de la pobreza, relacionada con la idea de que habría que formar capital humano para cortar con la transmisión intergeneracional de la pobreza: "Esta noción de capital humano aplicada a la pobreza renueva viejas representaciones de tipo civilizatorias y neocoloniales sobre los pobres que explican su causa en la falta de educación o de capacidades para realizar 'las mejores opciones' o de comportamientos considerados amorales" (ÁLVAREZ LEGUIZAMÓN, 2011, p. 271). En el mismo sentido, Fernández Soto (2013, p. 80) impugna la exigencia de las condicionalidades, en tanto "activa una dimensión punitiva-moralizante de control de buenos comportamientos de los pobres [...]. De esta manera se deja de lado el debate sobre la necesidad de transformaciones estructurales e institucionales para la superación de la pobreza".

Claramente, en términos de las tensiones puestas en juego en su formulación, fundamentación e implementación y en torno a la constitución del sujeto colocado como receptor de la intervención estatal, la AUH abre un escenario en el que es posible pensarla como un indicador de confrontaciones presentes en el gobierno de lo social de la Argentina contemporánea.

\section{Reflexiones finales}

Asistimos a un momento en que parecen entrar en contradicción distintas maneras de interrogar, definir y abordar la cuestión social, que se refleja en diferentes orientaciones de política social. Asimismo, los discursos que justifican y naturalizan dichas concepciones, también entran en tensión. Ese escenario, queda claramente manifiesto a partir de la Asignación Universal por Hijo. En ella conviven, como quisimos señalar, distintas lógicas de intervención social, aparentemente contradictorias y, al mismo tiempo, junto a ella se despliegan actualmente otras modalidades de gobierno de lo social, que también contienen elementos en tensión.

La racionalidad política neoliberal preconiza la individualidad como superación de cualquier atadura estatal que limite a las personas a realizar su máximo potencial y triunfar en el mercado. Ha quedado demostrado que los 
efectos de este proyecto han sido y son devastadores. Pertenecer a un colectivo no implica tutela estatal, sino garantía de seguridad social. Tal como sostiene Castel (2004b), no se pretende restaurar las protecciones vigentes en la época de consolidación del Estado social, pero tampoco resignarse a su abolición. Implica pensar al Estado como responsable de la integración social, que ampare derechos de ciudadanía al conjunto de la población, y repare los efectos causados por años de intervenciones de corte neoliberal. Una medida como la AUH señala un tipo de protección alternativa a la lógica dominante durante decenios, pero plantea asimismo una disputa por el sentido y la legitimidad de las intervenciones estatales en el gobierno de lo social.

La construcción de un Estado a la altura de los desafíos históricos exige nuevas intervenciones sociales, que cobijen un modo de pensarnos en sociedad como un colectivo, en sintonía con la apuesta a la defensa de una sociedad más justa y más igualitaria. La constitución del sujeto receptor de las políticas sociales está dada por la manera en que, históricamente, se construyen los problemas sociales, los cuales a su vez, expresan el modo en que es interrogada, pensada, la cuestión social. Constituir como objeto de la intervención estatal ciudadanos a ser protegidos, o pobres a ser corregidos, moralizados y/o tutelados, no es una mera cuestión terminológica, como hemos tratado de demostrar. Las consecuencias en términos de identidades colectivas del "pueblo trabajador" (MERKLEN, 2005) que en un país como el nuestro tenía una presencia de las más fuertes, tampoco son ingenuas.

Por último, el escenario abierto por la AUH, en la perspectiva aquí asumida, coloca interrogantes acerca del rol de los discursos de funcionarios, profesionales, y finalmente del discurso académico a la hora de hacer jugar argumentos para defender y/o criticar las intervenciones sociales estatales, y de elegir los fundamentos a los que se apela para tales fines. Cabe preguntarse qué consecuencias tienen nuestros modos de construir y hacer inteligibles los problemas sociales que pretendemos enfrentar.

\section{Referencias}

ÁLVAREZ LEGUIZAMÓN, S. La invención del desarrollo social en la Argentina: historia de 'opciones preferenciales por los pobres'. In: ANDRENACCI, L. (Comp.). Problemas de política social en la Argentina Contemporánea. Buenos Aires: Prometeo, 2006. p. 81-124. ÁLVAREZ LEGUIZAMÓN, S. Gubernamentalidad neoliberal y focopolítica en América Latina: los programas de transferencia condicionada. In: BARBA SOLANO, C. Y COHEN, N. Perspectivas críticas sobre la cohesión social: desigualdad y tentativas fallidas de integración social en América Latina. Buenos Aires: Consejo Latinoamericano de Ciencias Sociales, CLACSO, 2011.

ARCIDIÁCONO, P; CARMONA, V. Y STRASCHNOY, M. La Asignación Universal por Hijo para Protección Social: rupturas y continuidades ¿Hacia un esquema universal? Revista Margen, n. 61. Buenos Aires, 2011. Disponible en: <www.margen.org/suscri/ numero61.html>. Acceso en: agosto 2012.

ARGENTINA. Decreto del P. E. N., n 1602/ 09.

ARGENTINA. Ley Nacional $n^{\circ} 24.714$.

CAMPANA, M. Medicalizar la asistencia. Asistencializar la salud. Rosario: Prehistoria, 2012.

CASTEL, R. El ascenso de las incertidumbres. Trabajo, protecciones, estatuto del individuo. Buenos Aires: Fondo de Cultura Económica, 2010.

. Las metamorfosis de la cuestión social. Una crónica del salariado. Buenos Aires: Paidós, 2004a.

La inseguridad social. ¿Qué es estar protegido? Buenos Aires: Manantial, 2004b.

FERNÁNDEZ SOTO, S. La intervención social del Estado en los últimos años: el desplazamiento hacia la pobreza y la diversificación de programas asistenciales. Revista Escenarios. Buenos Aires: Espacio, UNLP, n. 14, p. 16-28, 2009.

FERNÁNDEZ SOTO, S. La política social y la recomposición material del consenso. La centralidad de los programas de Transferencia de Renta Condicionada: el caso argentino. Revista Serviço Social y Sociedade. San Pablo: Cortez, n. 113, p. 53-85, março 2013.

GIAVEDONI, J. Gobernando la pobreza. La energía eléctrica como dispositivo de gestioón de los sectores populares. Rosario: Homo Sapiens Ediciones, 2012a.

GIAVEDONI, J. Dispositivo e interpelación ideológica del sujeto- pobre. La construcción discursiva de la cuestión social en términos de pobreza. In: CAMPANA, M. y GIAVEDONI, J. (comps.). Estado, gobierno y gubernamentalidad. Notas sobre la razón gubernamental neoliberal en Argentina. Rosario: Ediciones Del Revés, 2012b.

GRASSI, E. Políticas y problemas sociales en la sociedad neoliberal. La otra década infame (I). Buenos Aires: Espacio, 2006.

HINTZE, S. Y COSTA, M. La reforma de las asignaciones familiares 2009: aproximación al proceso político de la transformación de la protección. In: DANANI, C. y HINTZE, S. (coords). Protecciones y desprotecciones: la seguridad social en la Argentina 1990- 2010. Buenos Aires: UNGS, 2011, p. 153-183. Disponible en: <http://www.ungs.edu.ar>. Acceso en: agosto 2011.

MERKLEN, D. Pobres ciudadanos. Las clases populares en la era democrática (Argentina, 1983-2003). Buenos Aires: Editorial Gorla, 2005.

MREJEN, M. Racionalidades políticas y políticas sociales. Un análisis de las Transferencias Condicionadas de Ingreso en la Argentina: el caso de la Asignación Universal por Hijo. Revista Cátedra Paralela Nº 10, Rosario: UNR Editora, 2013. p. 306-336. 
MURILLO, S. Naturalización de la pobreza y la desigualdad. Efectos políticos y subjetivos de las estrategias del Banco Mundial. Revista del CCC (Centro Cultural de la Cooperación Floreal Gorini) [PDF], No 1. Buenos Aires: septiembre 2007. Disponible en: <http://www.centrocultural.coop/modules/revista/pdf.php?que=1\&id=10> ISSN 1851-3263. Acceso en: octubre 2013.

MURILLO, S. (Coord.) Banco Mundial. Estado, mercado y sujetos en las nuevas estrategias frente a la cuestión social. Buenos Aires: Ediciones del Centro Cultural de la Cooperación Floreal Gorini, 2006.

ROCA, E., En: NERI, A. [et. al.] Asignación universal por hijo: ciclo de conferencias. Buenos Aires: AAPS, 2010. Disponible en: $\lfloor\underline{\text { http:/ }}$ /www.unicef.org/argentina/spanish/jornadas_asignacion_universal.pdf>. Acceso en: jul. 2011.

SOLDANO, D.; ANDRENACCI, L. Aproximación a las teorías de de la política social a partir del caso argentino. In: ANDRENACCI, L. (Comp.). Problemas de política social en la Argentina Contemporánea. Buenos Aires: Prometeo, 2006. p. 17-80.

\section{Notas}

1 "El Consenso de Washington es un conjunto de políticas económicas establecidas desde Washington con el acuerdo de organismos financieros internacionales. Fue formulado originalmente por John Williamson en un documento de noviembre de 1989, denominado 'What Washington means by policy reform', elaborado como documento de trabajo para una conferencia organizada por el Institute for International Economics. Según su autor, el texto era una lista de diez políticas pensadas originalmente para AL. No obstante, con los años se transformó en un programa general y se agregaron nuevas medidas: el programa se conoció finalmente como Neoliberalismo. La diez propuestas iniciales fueron: disciplina fiscal, reordenamiento del gasto público, reforma impositiva, liberalización de las tasas de interés, una tasa de cambio competitiva, liberalización del comercio internacional, liberalización de la entrada de inversiones extranjeras directas, privatización de empresas públicas, desregulación de la economía por parte de los estados, defensa de los derechos de propiedad. El significante 'Washington' tenía para Williamson el significado de un complejo intelectual-político y económico, con sede en esa ciudad: se trata de los organismos financieros internacionales (FMI, BM), el Parlamento norteamericano, la Reserva Federal, la cúpula de la Administración y los institutos de expertos (thinks tanks) en economía" (MURILLO, 2008, p. 85).

2 Dentro de este clima de época, Fernández Soto (2013, p. 65) destaca la emergencia de nuevos principios que deberían organizar la agenda de intervención: "la predominancia de lo público, la desmercantilización de los bienes y servicios sociales, la aspiración de garantías universales a través del reconocimiento de derechos históricamente conquistados, entre otras. Aunque lejos de concretarse, estas reivindicaciones al inicio del siglo 21 señalan y marcan rupturas con la hegemonía neoliberal, se expresan 'fisuras' a la subalternización desplegada a fines del siglo 20, y se despliegan una multiplicidad de prácticas 'antagonistas' como expresión de la negación del orden existente”.

3 En el año 1997 se creó la “Alianza por el Trabajo, la Justicia y laEducación”, que reunía a la Unión Cívica Radical y al Frente para un País Solidario (FREPASO). Luego, también recibió el apoyo de otros partidos políticos opuestos al gobierno nacional de entonces, presidido por Carlos Menem. La fórmula presidencial de la Alianza “De la Rúa-Álvarez” se impuso en los comicios de octubre de 1999.

4 Dentro de las medidas impulsadas por el gobierno nacional, en 2005 se realizó la renegociación de la deuda pública con una quita de capital cuantiosa; se canceló la deuda con el Fondo Monetario Internacional, eliminando así los condicionamientos del organismo internacional; y se rechazó el plan del Área de Libre Comercio de las Américas (ALCA) del presidente norteamericano Bush, al tiempo que se reforzó el Mercosur. Con la puesta en marcha del Consejo Nacional del Salario Mínimo Vital y Móvil y luego con las Convenciones Colectivas de Trabajo, se pugnó por el crecimiento del consumo y la creación de empleo. Entre las medidas de política social más importantes, además de las laborales, se destaca el Plan de inclusión previsional también conocido como moratoria jubilatoria. Ya durante la presidencia de Cristina Fernández, las más destacadas fueron la reforma del sistema previsional en el año 2008, eliminando el sistema de capitalización y re estatizando los fondos de las Administradoras de Fondos de Jubilaciones y Pensiones (AFJP); y la reforma del Sistema de Asignaciones Familiares, con la creación de la Asignación Universal por Hijo para Protección Social (AUH) por Decreto de necesidad y urgencia, No 1602, el 29 de octubre de 2009.

\section{Mariana Servio}

marianaservio@hotmail.com

Doutoranda de Trabajo Social pela Universidad Nacional de Rosario (UNR)

Professora da Universidad Nacional de Rosario (UNR)

\section{UNR - Facultad de Ciencia Política y RR II}

Riobamba 150 bis. Monoblock 1.

Rosario - Santa Fe - Argentina

S2000EKD 